\title{
Analysis of Power and Efficiency of Cross-flow Turbine Due to Changes in Runner Rotation
}

\section{Analisis Daya dan Efisiensi Turbin Cross-flow Akibat Perubahan Putaran Runner}

Lilik Darwito $^{1 *}$, Hendri Nurdin ${ }^{1}$, Purwantono $^{1}$, Andre Kurniawan ${ }^{1}$

\begin{abstract}
The Cross-flow turbine is one type of hydroelectric power plant that is frequently used. This is an experimental study with the goal of analyzing the power and efficiency produced by the turbine as a result of runner rotation adjustments. The runner rotation variations used are $261 \mathrm{rpm}, 300 \mathrm{rpm}, 320$ rpm, $340 \mathrm{rpm}, 360 \mathrm{rpm}, 380 \mathrm{rpm}, 392 \mathrm{rpm}$, and $423 \mathrm{rpm}$ with a head as high as 5 meters and an incoming water discharge of $0.2 \mathrm{~m}^{3} / \mathrm{s}$. The best results shown when runner rotate at $423 \mathrm{rpm}$. It's showed the maximum power 788.85 Watt and best efficiency $80.49 \%$. The power and efficiency produced by a runner are proportional to the rotational speed of the runner; the higher the runner's rotation, the greater the power and efficiency produced. To summarize, the best way to achieve the best turbine performance is to maximize runner rotation.
\end{abstract}

\section{Keywords}

Cross-flow Turbine, Runner Rotation, Power, Efficiency

\begin{abstract}
Abstrak
Salah satu jenis pembangkit listrik tenaga air yang sering digunakan adalah turbin tipe Cross-flow. Penelitian ini berupa penelitian eksperimen yang bertujuan untuk menganalisis daya dan efisiensi yang dihasilkan turbin akibat perubahan putaran runner. Variasi putaran runner yang digunakan yaitu $261 \mathrm{rpm}, 300 \mathrm{rpm}, 320 \mathrm{rpm}, 340 \mathrm{rpm}, 360 \mathrm{rpm}, 380 \mathrm{rpm}, 392 \mathrm{rpm}$, dan $423 \mathrm{rpm}$ dengan head setinggi 5 meter serta debit air yang masuk $0,2 \mathrm{~m}^{3} / \mathrm{s}$. Hasil penelitian menunjukkan daya dan efisiensi maksimum didapatkan pada putaran runner $423 \mathrm{rpm}$ yaitu 788,85 Watt dengan efisiensi 80,49\%. Terbukti bahwa daya dan efisiensi sebanding dengan kecepatan putaran runner, semakin tinggi putaran runner maka daya dan efisiensi yang dihasilkan juga semakin besar. Dapat disimpulkan, untuk mendapatkan kinerja turbin yang maksimal yaitu dengan memaksimalkan putaran runner.
\end{abstract}

\section{Kata Kunci}

Turbin Cross-flow, Putaran Runner, Daya, Efisiensi

${ }^{1} J u r u s a n$ Teknik Mesin, Fakultas Teknik, Universitas Negeri Padang

Jl. Prof. Dr. Hamka, Air Tawar, Padang 25131, Indonesia

*darwitolilik@gmail.com

Submitted : January 25, 2022. Accepted : February 24, 2022. Published : February 25, 2022. 


\section{PENDAHULUAN}

Air merupakan salah satu bentuk tenaga yang dapat dimanfaatkan sebagai sumber energi alternatif untuk menggantikan bahan bakar fosil yang saat ini sudah semakin berkurang. Tenaga air saat ini banyak dimanfaatkan sebagai pembangkit listrik pada daerah terpencil yang belum terjangkau listrik namun memiliki potensi aliran sungai yang cukup [1]. Pembangkit Listrik Tenaga Air memanfaatkan air untuk memutar generator dengan mengubah energi potensial dan energi kinetik air untuk menghasilkan energi listrik [2]. Jenis pembangkit listrik yang sering digunakan adalah pembangkit listrik pico hydro. Pico hydro adalah istilah yang digunakan untuk pembangkit listrik tenaga air di bawah $5 \mathrm{Kw}$ [3].

Pembangkit listrik tenaga pico hydro merupakan salah satu alternatif pembangkit listrik skala kecil yang dapat diterapkan di daerah pedesaan dimana tersedia aliran sungai yang mempunyai debit air yang kontinu untuk menghasilkan daya listrik [4]. Prinsip kerja dari Pembangkit Listrik Tenaga Pico Hydro (PLTPH) ini adalah memanfaatkan beda ketinggian dan jumlah debit air per detik yang ada pada aliran air saluran irigasi, sungai atau air terjun [5]. Aliran air ini akan memutar poros turbin sehingga menghasilkan energi gerak yang selanjutnya energi gerak tersebut dikonversi menjadi energi listrik oleh generator pada turbin [6]. Turbin air inilah yang digunakan untuk mengubah energi potensial air menjadi energi mekanik [7]. Selanjutnya energi mekanik ini akan diubah menjadi energi listrik oleh generator turbin.

Berdasarkan prinsip kerjanya turbin dibedakan menjadi dua yaitu turbin impuls dan turbin reaksi. Turbin impuls adalah turbin air yang bekerja dengan mengubah seluruh energi air yang terdiri dari energi potensial, tekanan, kecepatan menjadi energi kinetik untuk memutar turbin, sehingga menghasilkan energi listrik [8]. Contoh jenis tubin impuls yaitu turbin Pelton, turbin Turgo dan turbin Cross-flow [9]. Jenis turbin yang digunakan pada penelitian ini yaitu turbin Cross-flow dengan ketinggian jatuh air (head) berkisar 5 meter. Turbin tipe Cross-flow merupakan jenis turbin air bertekanan yang sering dipakai pada pembangkit listrik tenaga air (PLTA) yang merupakan salah satu contoh dari pembangkit listrik pico hydro [10].

Komponen utama turbin terdiri dari rotor dan stator. Rotor adalah bagian yang berputar pada sistem seperti sudu, poros dan bantalan [11]. Sedangkan stator adalah bagian diam yang ada pada sistem yang terdiri dari nozel dan rumah turbin. Pada rumah turbin terdapat nozel sebagai tempat aliran air masuk, kemudian di dalam nozel diberi guide vane (katup) yang berfungsi mengatur debit air yang masuk untuk memutar runner turbin [12].

Tuntutan utama dari perancangan turbin Cross-flow ini yaitu untuk menyesuaikan kondisi lapangan dengan bentuk turbin yang akan di pasang sehingga menghasilkan listrik yang optimal. Nagari Tandikek Utara yang berada di Kabupaten Padang Pariaman dipilih sebagai lokasi pemasangan turbin tipe Cross-flow ini karena daerah ini masih sulit mendapatkan pasokan energi listrik yang cukup, dan memiliki potensi aliran air sungai yang cocok untuk memutar generator tipe Cross-flow.

Pada penelitian ini turbin akan diuji coba, kemudian datanya akan dianalisa guna melihat besarnya daya serta efisiensinya saat terjadi perubahan tingkat putaran runner. Variasi putaran runner dilakukan dengan melakukan variasi bukaan sudut guide vane yang digunakan. Dari analisa tersebut akan diketahui pada putaran berapa turbin menghasilkan daya dan efisiensi maksimlnya. Penelitian sebelumnya pernah dilakukan pada tahun 2016 oleh Muliawan dengan nilai putaran runner serta jumlah sudu yang berbeda. Pada penelitian tersebut dihasilkan efisiensi sebesar $28,34 \%$ pada tingkat putaran runner $70 \mathrm{rpm}$ [17]. 


\section{METODE PENELITIAN}

Penelitian ini berupa penelitian eksperimen yang bertujuan untuk menganalisis daya dan efisiensi yang dihasilkan turbin akibat perubahan putaran runner. Variabel bebas pada penelitian ini berupa variasi putaran runner yang digunakan yaitu $261 \mathrm{rpm}, 300 \mathrm{rpm}, 320$ rpm, 340 rpm, 360 rpm, 380 rpm, 392 rpm, dan 423 rpm. Penelitian ini dilakukan di Nagari Tandikek Utara, Kabupaten Padang Pariaman. Daerah ini merupakan salah satu daerah yang masih sulit mendapatkan aliran listrik. Berikut adalah rancangan turbin yang dibuat menggunakan aplikasi Autodesk Inventor Professional 2017 ditunjukkan oleh Gambar 1.
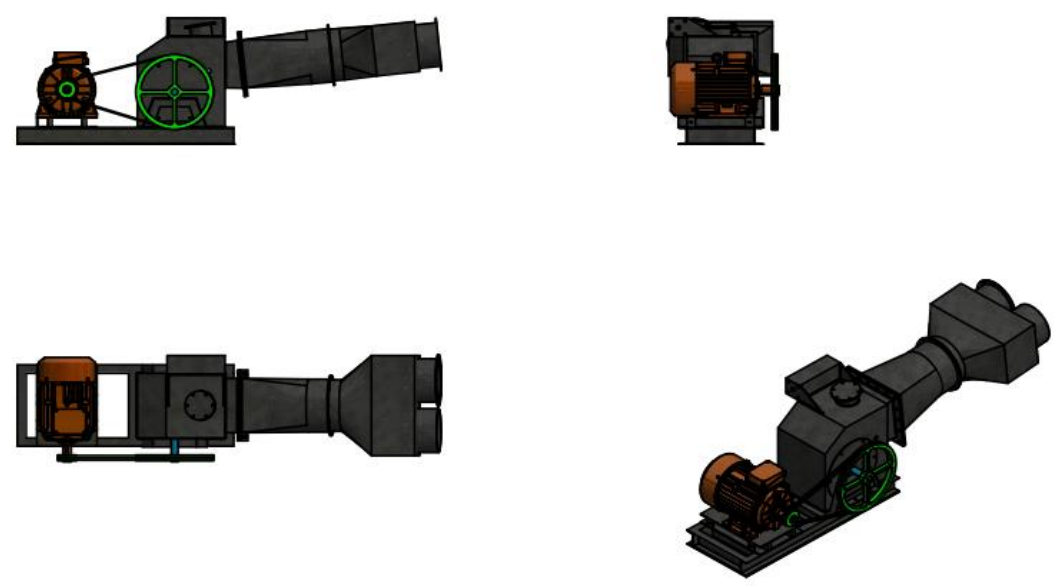

Gambar 1. Rancangan Turbin Cross-flow

Turbin Cross-flow yang telah dibuat selanjutnya di pasang dengan head (ketinggian air jatuh) 5 meter serta debit air $0,2 \mathrm{~m}^{3} / \mathrm{s}$. Berikut adalah gambar alat yang sudah terpasang dengan input debit air sungai serta output daya generator pada ditunjukkan oleh Gambar 2.

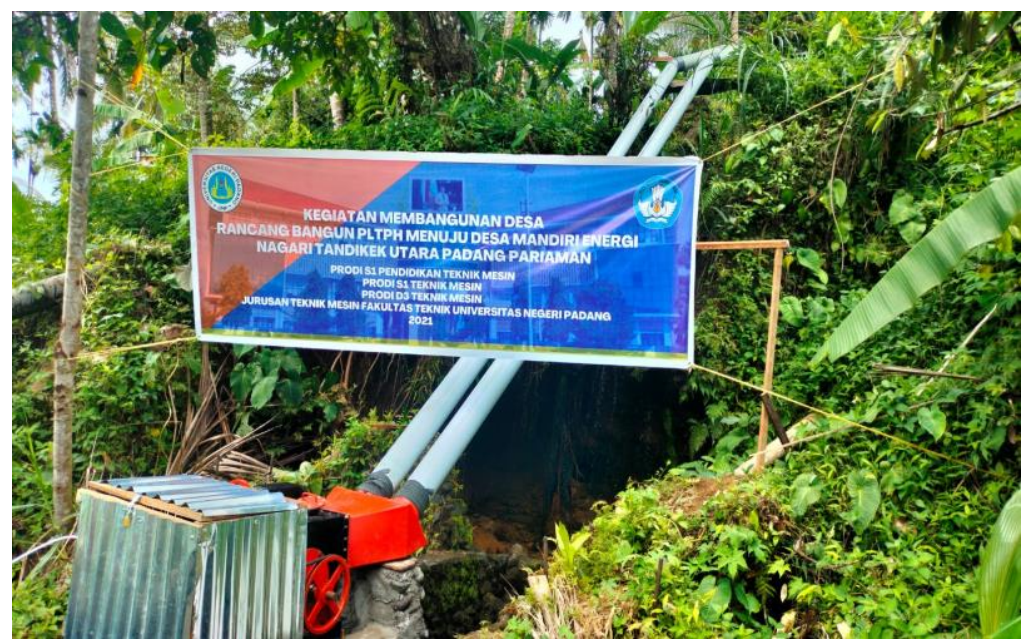

Gambar 2. Turbin Cross-flow dengan input debit air dan output daya generator

Setelah pemasangan alat dilakukan proses untuk mencari nilai putaran runner yang digunakan yaitu $261 \mathrm{rpm}, 300 \mathrm{rpm}, 320 \mathrm{rpm}, 340 \mathrm{rpm}, 360 \mathrm{rpm}, 380 \mathrm{rpm}, 392 \mathrm{rpm}$ dan 423 rpm. Untuk mendapatkan variasi putaran ini yaitu dengan memvariasikan bukaan sudut guide vane pada turbin yang selanjutnya diukur menggunakan tachometer. Persentasi bukaan guide vane yang digunakan diambil dari pengukuran sudut yang dibuka dikurang dengan total Keseluruhan sudut bukaan yang ada. Gambar 3 berikut adalah salah satu bentuk variasi bukaan sudut guide vane yang digunakan untuk mengukur nilai putaran runner. 


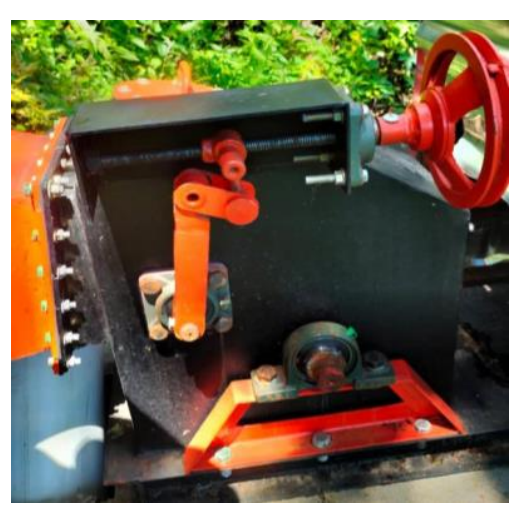

Gambar 3. Bentuk Variasi Bukaan Sudut Guide Vane yang digunakan

Setelah mendapatkan variasi putaran runner yang digunakan selanjutnya dilakukan pengukuran berupa nilai tegangan dan arus yang dihasilkan oleh turbin menggunakan multimeter. Pengukuran ini dilakukan pada generator turbin dengan menggunakan multimeter untuk mendapatkan nilai tegangan dan arus yang dihasilkan oleh masing-masing variasi putaran runner. Berikut adalah gambar proses pengambilan data yang dilakukan dilapangan ditunjukkan oleh Gambar 4.

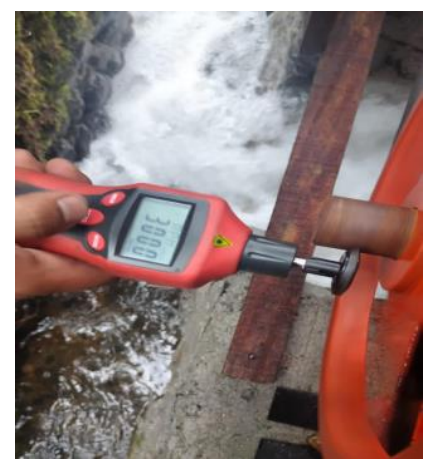

Gambar 4. Proses Pengambilan Data

Setelah tahap pengukuran dilakukan, selanjutnya data yang telah didapatkan diolah menggunakan persamaan yang ada dan dilakukan analisis. Berikut adalah rumus perhitungan yang digunakan untuk menentukan debit air yang masuk [10]:

$$
Q=v \boldsymbol{x} A
$$

Keterangan: $\mathrm{Q}=$ debit air yang masuk $\left(\mathrm{m}^{3} / \mathrm{s}\right)$

$\mathrm{v}=$ kecepatan aliran $\operatorname{air}(\mathrm{m} / \mathrm{s})$

$\mathrm{A}=$ luas permukaan $\left(\mathrm{m}^{2}\right)$

Dimana untuk mencari debit terlebih dahulu menentukan kecepatan air dengan rumus [2]:

Keterangan: $\mathrm{v}=$ kecepatan air $(\mathrm{m} / \mathrm{s})$

$$
v=\sqrt{2 x g x H} \text {. }
$$

$\mathrm{g}=\operatorname{gravitasi}\left(\mathrm{g}=9,8 \mathrm{~m} / \mathrm{s}^{2}\right)$

$\mathrm{H}=$ head $(\mathrm{m})$

Setelah didapatkan nilai debit air selanjutnya yaitu menentukan nilai daya air $\left(\mathrm{P}_{\mathrm{air}}\right)$ dengan persamaan sebagai berikut [13]:

$$
P_{\text {air }}=\rho x g x H x Q \text {. }
$$

Keterangan: $P_{\text {air }}=$ daya air $($ Watt $)$

$\rho=$ massa jenis air $\left(\mathrm{Kg} / \mathrm{m}^{3}\right)$ 


$$
\begin{aligned}
& \mathrm{g}=\operatorname{gravitasi}\left(\mathrm{g}=9,8 \mathrm{~m} / \mathrm{s}^{2}\right) \\
& \mathrm{H}=\operatorname{head}(\mathrm{m}) \\
& \mathrm{Q}=\operatorname{debit} \text { air yang masuk }\left(\mathrm{m}^{3} / \mathrm{s}\right)
\end{aligned}
$$

Hasil pengukuran berupa tegangan dan arus digunakan untuk mencari nilai dan efisiensi turbin menggunakan persamaan berikut [14]:

$$
P_{\text {out }}=V \boldsymbol{x} I \text {. }
$$

Keterangan: $P_{\text {out }}=$ daya keluaran $($ Watt $)$

$$
\begin{aligned}
& \mathrm{V}=\text { tegangan (Volt) } \\
& \mathrm{I}=\text { arus (Ampere) }
\end{aligned}
$$

Daya listrik yang telah didapatkan digunakan untuk mencari nilai efisiensi turbin menggunakan rumus sebagai berikut [13]:

$$
\mathrm{\eta}_{t}=\frac{P_{\text {out }}}{P_{\text {air }}} \times 100 \%
$$

Keterangan: $\eta_{t}=$ Efisiensi turbin (\%)

$P_{\text {out }}=$ daya keluaran $($ Watt $)$

$P_{\text {air }}=$ daya air $($ Watt $)$

\section{HASIL DAN PEMBAHASAN}

\section{Hasil}

Hasil pengukuran berupa nilai tegangan dan arus dari variasi putaran runner yang digunakan yaitu $261 \mathrm{rpm}, 300 \mathrm{rpm}, 320 \mathrm{rpm}, 340 \mathrm{rpm}, 360 \mathrm{rpm}, 380 \mathrm{rpm}, 392 \mathrm{rpm}$, dan 423 rpm. Data pendukung lainnya yaitu Head (ketinggian) yang digunakan yaitu 5 meter, jumlah sudu yang digunakan sebanyak 20 buah, diameter pipa 15,8 cm dan panjang pipa 16,6 meter dengan debit air yang masuk yaitu $0,2 \mathrm{~m}^{3} / \mathrm{s}$. Nilai daya dan efisiensi rata-rata masing-masing variasi putaran runner ditunjukkan pada Tabel 1 berikut.

Tabel 1. Hasil Perhitungan Rata-rata Daya Keluaran dan Efisiensi Turbin

\begin{tabular}{|c|c|c|c|c|c|}
\hline $\begin{array}{c}\text { Putaran } \\
\text { Runner } \\
\text { (Rpm) }\end{array}$ & $\begin{array}{c}\text { Sudut } \\
\text { Bukaan Guide } \\
\text { Vane ( } \mathbf{(})\end{array}$ & $\begin{array}{c}\text { Tegangan } \\
\text { (Volt) }\end{array}$ & $\begin{array}{c}\text { Arus } \\
\text { (A) }\end{array}$ & $\begin{array}{c}\text { Daya Keluaran } \\
\text { (Watt) }\end{array}$ & $\begin{array}{c}\text { Efisiensi } \\
\text { (\%) }\end{array}$ \\
\hline 261 & 76,5 & 24,16 & 0,23 & 5,56 & 0,57 \\
\hline 300 & 49,5 & 51,53 & 1,72 & 88,63 & 9,04 \\
\hline 320 & 44,1 & 77,90 & 2,54 & 197,87 & 20,19 \\
\hline 340 & 37,8 & 91,10 & 3,11 & 283,32 & 28,91 \\
\hline 360 & 32,4 & 105,50 & 3,70 & 390,35 & 39,83 \\
\hline 380 & 27 & 129,50 & 4,21 & 545,20 & 55,63 \\
\hline 392 & 4,5 & 130,60 & 4,45 & 581,17 & 59,30 \\
\hline 423 & 13,5 & 146,90 & 5,37 & 788,85 & 80,49 \\
\hline
\end{tabular}

Tabel 1 menunjukkan nilai rata-rata daya dan efisiensi dihasilkan oleh turbin. Pengukuran dilakukan masing-masing variasi sebanyak 3 kali percobaan agar data didapat lebih akurat dan mengurangi kesalahan yang terjadi. Hasil perhitungan daya untuk masingmasing variasi yang digunakan yaitu 5,56 Watt, 88,63 Watt; 197,87 Watt; 283,32 Watt; 390,35 Watt; 545,20 Watt; 581,17 Watt dan 788,85 Watt. Efisiensi turbin yang dihasilkan yaitu 0,57\%; 9,04\%; 20,19\%; 28,91\%; 39,83\%; 55,63\%; 59,30\% dan 80,49\%. Untuk melihat 
hubungan antara perubahan putaran runner dan daya turbin yang dihasilkan ditunjukkan oleh Gambar 5 berikut.

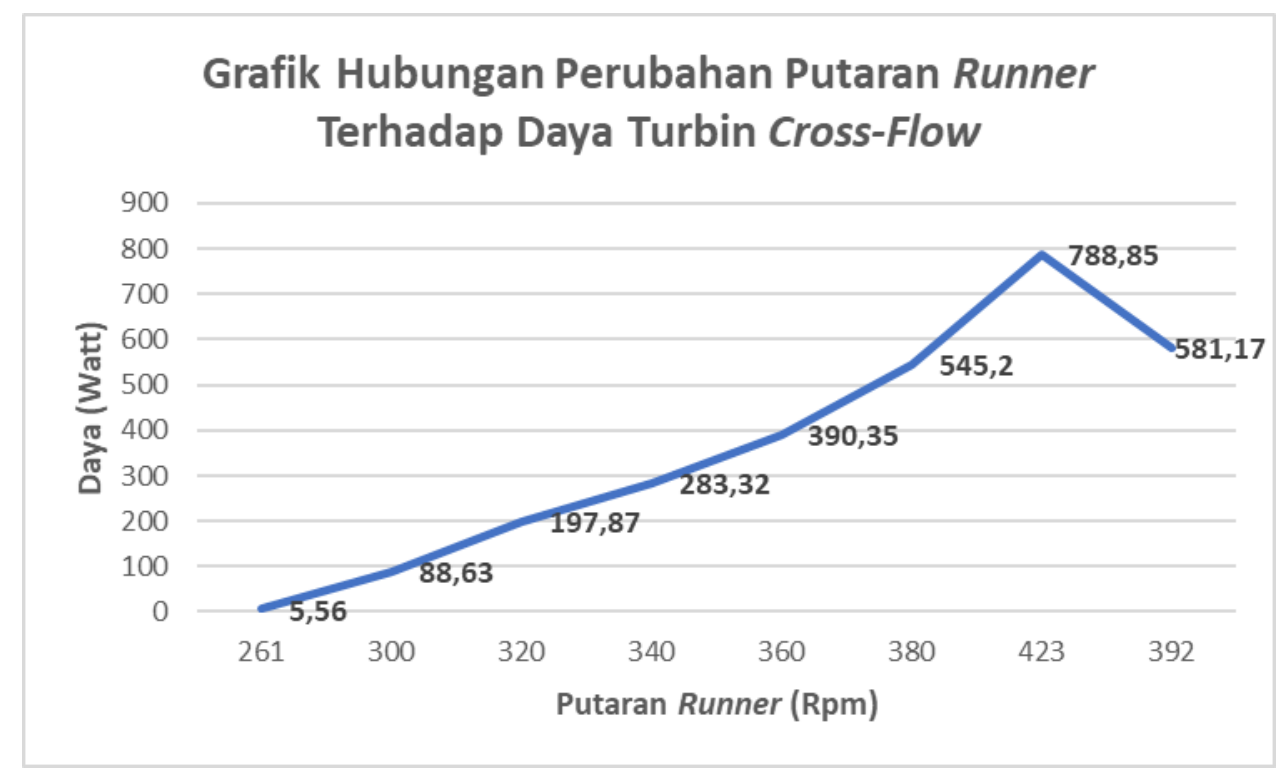

Gambar 5. Grafik hubungan perubahan putaran runner dengan daya turbin yang dihasilkan

Gambar 5 di atas menunjukkan hubungan pengaruh perubahan putaran runner terhadap daya listrik yang dihasilkan. Grafik menunjukkan hubungan linear atau sebanding antara putaran runner yang digunakan dan daya listrik yang dihasilkan. Namun setelah mencapai putaran runner maksimum daya yang dihasilkan mengalami penurunan hal ini dikarenakan bukaan sudut yang digunakan juga semakin kecil. Selain itu putaran runner juga berpengaruh terhadap efisiensi turbin yang dihasilkan, hubungan antara putaran runner dan efisiensi dapat dilihat pada Gambar 6 berikut.

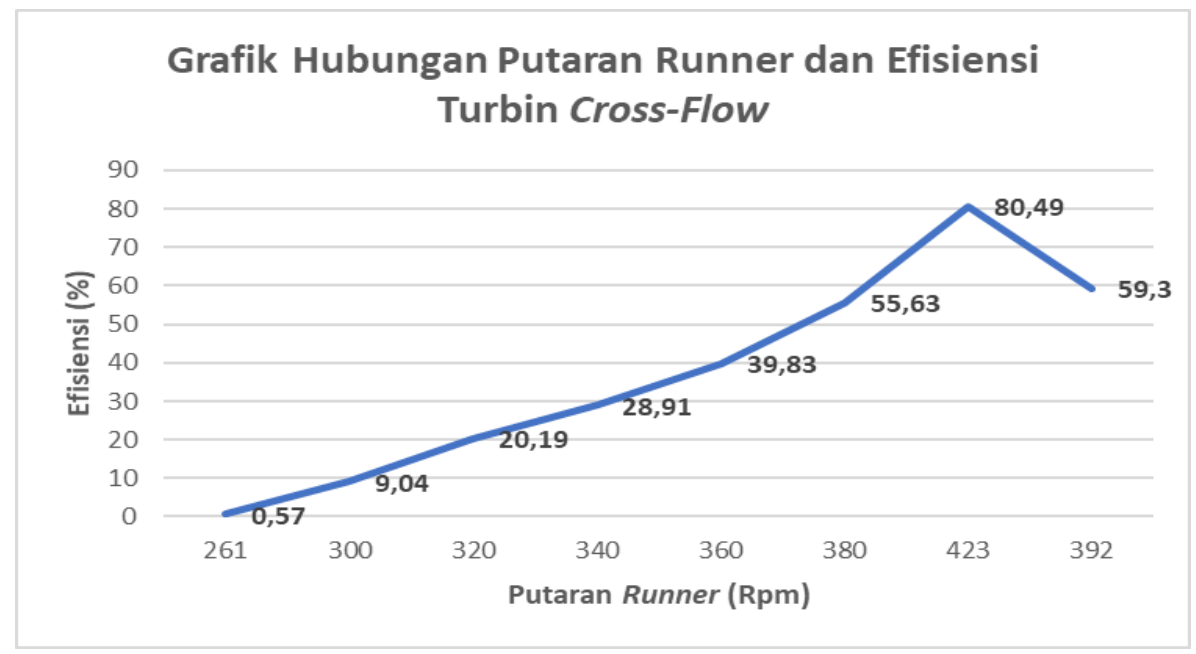

Gambar 6. Grafik hubungan perubahan putaran runner dan efisiensi turbin

Gambar 6 menunjukkan grafik hubungan putaran runner yang digunakan dengan efisiensi turbin yang dihasilkan. Sama halnya dengan daya, efisiensi turbin juga akan semakin tinggi jika putaran runner yang digunakan juga besar. Hal ini terlihat pada gambar yang mengalami peningkatan seiring putaran runner yang digunakan, namun setelah mencapai putaran runner maksimum efisiensi yang dihasilkan semakin kecil karena putaran runnernya mengalami 
penurunan. Hal ini menunjukkan bahwa putaran runner yang digunakan juga berpengaruh terhadap efisiensi turbin yang dihasilkan.

\section{Pembahasan}

Hasil perhitungan berupa daya dan efisiensi turbin yang dihasilkan menggunakan variasi putaran runner. Hasil perhitungan menunjukkan bahwa daya listrik yang dihasilkan akan semakin besar jika putaran runner yang digunakan juga semakin besar. Dari variasi putaran runner yang digunakan nilai daya maksimal didapatkan pada putaran 423 rpm yaitu 788,85 Watt dengan efisiensi $80,49 \%$. Hal ini juga terlihat pada grafik hubungan putaran runner terhadap daya dan efisiensi. Dan nilai daya minimum dihasilkan pada putaran runner $261 \mathrm{rpm}$ yaitu 5,56 Watt dengan efisiensi 0,57\%. Variasi nilai putaran runner ini juga diambil dari penelitian sebelumnya yang pernah dilakukan oleh Irawan (2018) yang menyebutkan putaran runner maksimal yaitu 321,1 rpm dengan bukaan sudut 75\% [15] serta Sunardi (2016) menyebutkan bahwa putaran runner maksimum yang didapatkan yaitu 373 rpm dan minimum $291 \mathrm{rpm}$ [16].

Hubungan antara perubahan putaran runner dengan daya dan efisiensi turbin ditunjukkan oleh grafik pada Gambar 5 dan Gambar 6. Dari grafik menunjukkan bahwa hubungan putaran runner dengan daya dan efisiensi yang dihasilkan sebanding/linear, namun mengalami penurunan setelah mencapai putaran maksimum. Daya yang dihasilkan turbin bergantung pada nilai putaran runner sedangkan nilai efisiensi turbin tergantung pada nilai daya yang dihasilkan [17]. Hal ini sesuai dengan penelitian sebelumnya yang dilakukan oleh Muliawan (2016) yang menyebutkan bahwa semakin besar kecepatan putaran runner yang digunakan maka daya dan efisiensi yang dihasilkan juga semakin besar [17]. Dari penelitian yang telah dilakukan berharap agar alat ini dapat membantu masyarakat setempat dan menjadi contoh untuk daerah lainnya yang masih kesulitan mendapatkan aliran listrik. Untuk mendapatkan hasil kerja turbin yang maksimal peneliti menyarankan agar menggunakan putaran runner yang maksimal serta bukaan guide vane yang minimum.

\section{SIMPULAN DAN SARAN}

\section{Simpulan}

Berdasarkan penelitian yang telah dilakukan maka dapat disimpulkan dua hal. Pertama, variasi putaran runner yang digunakan berpengaruh terhadap daya turbin yang dihasilkan. Dimana semakin besar nilai putaran runner yang digunakan maka daya yang dihasilkan juga akan semakin besar. Dari variasi putaran runner yang digunakan, daya maksimal yang didapatkan yaitu 788,85 Watt pada putaran runner 423 rpm. Kedua, variasi putaran runner yang digunakan berpengaruh terhadap efisiensi yang dihasilkan. Efisiensi juga dipengaruhi oleh daya yang dihasilkan. Dimana semakin besar nilai putaran runner maka daya yang dihasilkan semakin besar dan nilai efisiensi yang dihasilkan juga akan semakin besar. Dari variasi putaran runner yang digunakan, nilai efisiensi maksimal yang didapatkan yaitu 80,49\% pada putaran runner $423 \mathrm{rpm}$.

\section{Saran}

Berdasarkan penelitian yang telah dilakukan, untuk penelitian selanjutnya menambahkan corong pada penstock sebelum terhubung langsung ke guide vane agar lebih efisien dan aliran air yang masuk lebih maksimal. 


\section{DAFTAR RUJUKAN}

[1] Kelian, M. A. S. (2018). Kajian Potensi Pembangkit Listrik Tenaga Mikrohidro Di Sungai Wae Bobot Kecamatan Werinama Kabupaten Seram Bagian Timur. Jurnal Simetrik Vol.7, No.1, Juni 2017. 7(1), 8-12.

[2] Astro, R. B., Doa, H., \& Hendro, H. (2020). Fisika Kontekstual Pembangkit Listrik Tenaga Mikrohidro. Orbita: Jurnal Kajian, Inovasi Dan Aplikasi Pendidikan Fisika, 6(1), 142. https://doi.org/10.31764/orbita.v6i1.1858

[3] Anwar, S., Tamam, M. T., \& Kurniawan, I. H. (2021). Rancang Bangun Sistem Pembangkit Listrik Tenaga Air Menggunakan Konsep Hydrocat. RESISTOR (Elektronika Kendali Telekomunikasi Tenaga Listrik Komputer), 4(1), 7.

[4] Nakhoda, Y. I., Sulistiawati, I. B., Soetedjo, A. (2018). Penerapan Pembangkit Listrik Tenaga Pikohidro. Jurnal Aplikasi Dan Inovasi Ipteks “Soliditas” (J-Solid). 5068, 99-109.

[5] Alipan, N., \& Yuniarti, N. (2018). Pengembangan Pembangkit Listrik Tenaga Pico-Hydro. Jurnal Edukasi Elektro. 2(2), 59-70.

[6] Elbatran, A. H., Abdel-hamed, M. W., Yaakob, O. B., Ahmed, Y. M., \& Ismail, M. A. (2015). Jurnal Teknologi Hydro Power and Turbine Systems Reviews. 5, 83-90.

[7] Suswantoro, E., Gani, U. A., Taufiqurrahman. (2021). Analisis Pengaruh Jumlah Sudu Turbin Air Tipe Crossflow Terhadap Output PLTMH Skala Laboratorium. 2(1), 81-89.

[8] Harahap, P., \& Laksono, H. A. (2019). Analisa Perbandingan Pengaruh Variasi Jumlah Sudu 4 Dan 8 Pada Turbin Angin Savonius Terhadap Tegangan Dan Arus Generator Dc. Jurnal Teknik Elektro. 2(1), 1-8.

[9] Kaniecki, M. (2016). Modernization Of The Outflow System Of Cross-Flow Turbines Modernization Of The Outflow System Of Cross-Flow Turbines. January 2002, 2008-2010.

[10] Riadi, D., Lapisa, R., Nurdin, H., \& Mulianti, M. (2021). Analisis Kecepatan Air Masuk Terhadap Bukaan Guide Vane Turbin Cross-Flow Skala Pico Hydro Dengan Simulasi Cfd. Jurnal Vokasi Mekanika (Vomek), 3(3), 94-101.

[11] Misbachudin Muh, Desylita Subang, Tri Wadagdo, Dan Moch. Yunus. (2016). Perancangan Pembangkit Listrik Tenaga Mikro Hidro Di Desa Kayuni Kabupaten Fakfak Provinsi Papua Barat. Jurnal Austenit. 8, 1-12.

[12] Mehr, G., Durali, M., Khakrand, MH, \& Hoghooghi, H. (2021). Sebuah desain baru dan metodologi optimasi kinerja untuk turbin Cross-Flow hidrolik menggunakan simulasi numerik berturut-turut. Energi Terbarukan , 169, 1402-1421.

[13] Tirono, Mokhamad. Pemodelan Turbin Cross-flow Untuk Diaplikasikan Pada Sumber Air Dengan Tinggi Jatuh Dan Debit Kecil. Jurnal Neutrino: Jurnal Fisika dan Aplikasinya. April 2012. https://doi.org/10.18860/neu.v0i0.1939

[14] Mafruddin and Irawan, D. (2018). Pengaruh Diameter dan Jumlah Sudu Runner Terhadap Kinerja Turbin Cross-Flow. Turbo: Jurnal Program Studi Teknik Mesin 7, no. 2.

[15] Irawan, H. (2018). \& Syamsuri, S. (2018). Analisis Performansi Sistem Pembangkit Listrik Tenaga Air Turbin Pelton Dengan Variasi Bukaan Katup Dan Beban Bola Lampu Menggunakan Inverter. JHP17: Jurnal Hasil Penelitian. 03(02), 80-85.

[16] Sunardi, A., Hanun, Y. (2016). Pengaruh Perbandingan Runner Terhadap Performa Turbin Vertikal Bertingkat Dua. Cyberpreneurship Innovative and Creative Exact and Social Science. 2(2), 188-194.

[17] Muliawan, A., \& Yani, A. (2016). Analisis Daya Dan Efisiensi Turbin Air Kinetis Akibat Perubahan Putaran Runner. Saintek: Jurnal Sains dan Teknologi. 8(1), 1-9. 